\title{
Is the body composition equal or more important in physical fitness variables than other features like age or sex within physical education classes? A theoretical-practice study
}

\author{
Emilio J. Martínez-López ${ }^{1}$, Sebastián López-Serrano ${ }^{1}$, Sara Suárez-Manzanoํㅡ, and Alberto \\ Ruiz-Ariza ${ }^{1 \mathrm{a}}$ \\ ${ }^{1}$ Faculty of Humanities and Education Sciences, University of Jaen, Campus Las Lagunillas s/n, Jaen, \\ Spain
}

\begin{abstract}
The aim was to quantify the influence of body composition on the strength and cardiovascular endurance in adolescents. 858 Spanish adolescents participated in this pilot study. BMI values, standing jump test and Course Navette test were analyzed. The degree of influence of BMI was calculated by effect size. In the standing jump test, only between 18$25 \%$ of boys and between $17-36 \%$ of overweight girls got a distance equal or greater than those with normalweight. In Course Navette, only between $9 \%-19 \%$ of the boys and $23 \%-35 \%$ of overweight girls got equal or greater scores than those with normalweight. It is concluded that only a small percentage of adolescent overweight reach outcomes in strength and cardiovascular endurance equal or greater than the normalweight students. These results suggest that it would be necessary to include the body composition variable within the scales of scholar physical fitness test in young people.
\end{abstract}

Keywords: Physical education, body composition, adolescent.

\section{Introduction}

Health-related physical fitness is defined as the ability of a person to perform daily activities with vigor [1]. One way to assess physical fitness through the test or battery test of fitness. These are the different components of the same and individually as a whole, are related to sports performance or to the specific health and future of a person [2].

At present, there are more than 15 batteries and dozens of tests to assess physical fitness in children and adolescents [11]. Different researches have shown that physical fitness is higher in boys than girls [1, 3-5], Ortega et al. [5], have shown that levels of strength,

\footnotetext{
${ }^{\text {a }}$ Corresponding author: arariza@ujaen.es
} 
speed/agility performance, and aerobic capacity are greater in adolescent boys, except flexibility where girls obtain higher results [5-6].

Another important fact is that adolescent boys increase physical fitness levels with increasing age, while in girls it is observed a maintenance level [2, 5-6]. Despite of these important variables, in the last years there is another variable that could mediate in the physical fitness scales in adolescents. In developed societies, obesity has been developed as the most frequent nutritional disorder during childhood and adolescence, and its prevalence has increased progressively during the last decades [7].

In relation to the developed countries, Spain presents very high values of obesity. In recent years, trends indicate an increase in the prevalence of overweight and obesity in children and adolescents [8], and the low levels of physical activity practice are some of the most determinant factors [9]. This increase in overweight can lead to significant limitations in physical fitness tests among young people and significantly affect the performance of adolescents during Physical Education classess [10-11]. In other words, physical fitness in adolescents is significantly better in normalweight than in overweight or obese people [2, $11]$.

\section{Objective}

Based on the above, this study aimed to quantify the influence of body typology (normalweight or overweight+obesity) on strength and cardiovascular endurance, measured with physical fitness test, in Spanish adolescents.

\section{Methodology}

\subsection{Participants}

The present descriptive-cross-sectional pilot study involved 858 adolescents ( 453 boys and 405 girls) and a BMI of $22.3 \pm 3.9 \mathrm{~kg} / \mathrm{m} 2$. The sample was for convenience. Data were collected from 8 Spanish secondary schools. The study was approved by the Bioethics Commission of the University of Jaén (Spain), with the consent of the parents or legal guardians. Participants were categorized into normalweight and overweight (overweight + obesity) adolescents, according to the specific cut-off points for each sex and age proposed by the Orbegozo Foundation's Research Institute on Growth and Development [12]. 
Table 2. Anthropometric characteristics and physical fitness parameters of the study sample according to sex.

\begin{tabular}{llllll}
\hline & $\begin{array}{l}\text { All } \\
(\mathrm{n}=858)\end{array}$ & $\begin{array}{l}\text { Boys } \\
(\mathrm{n}=453)\end{array}$ & $\begin{array}{l}\text { Girls } \\
(\mathrm{n}=405)\end{array}$ & $\begin{array}{l}\text { Sex } \\
\text { Differences }\end{array}$ & $\begin{array}{l}\text { Trending } \\
\text { Age }\end{array}$ \\
\hline Age & $14.5(1.3)$ & $14.3(1.3)$ & $14.4(1.3)$ & $=$ & - \\
\hline Wight $(\mathrm{kg})$ & $59.6(13.6)$ & $63.12(14.7)$ & $56.3(11.42)$ & $>$ & $>$ \\
\hline Height $(\mathrm{m})$ & $1.6(0.2)$ & $1.7(0.2)$ & $1.6(0.2)$ & $>$ & $>$ \\
\hline BMI $\left(\mathrm{kg} / \mathrm{m}^{2}\right)$ & $22.1(4.1)$ & $22.2(4.3)$ & $21.9(4.1)$ & $>$ & $>$ \\
\hline Normalweight $(\%)$ & 72.4 & 73.5 & 71.3 & $=$ & $>$ \\
\hline Overweight $(\%)$ & 27.6 & 26.5 & 28.7 & $=$ & $>$ \\
\hline $\begin{array}{l}\text { Longitudinal Jump } \\
(\mathrm{cm})\end{array}$ & $153.3(33.6)$ & $172.8(30.6)$ & $132.5(22.4)$ & $>$ & $>$ \\
\hline $\begin{array}{l}\text { VO2Max course navette } \\
(\mathrm{ml} / \mathrm{Kg} / \text { min })\end{array}$ & $41.9(7.1)$ & $45.2(6.6)$ & $38.3(5.1)$ & $>$ & $<$ \\
\hline
\end{tabular}

Data are expressed as mean (SD). The $>$ symbol in "sex differences", means that the variable is significantly higher in men than in women $(\mathrm{p}<0.05)$; On the contrary; $=$, There are no significant differences. The $>$ symbol in "trending age" refers to that variable tends to increase with increasing age ( $\mathrm{p}<0.05)$; On the contrary; - not applicable.

\subsection{Process}

The level of muscular strength and cardiovascular endurance was assessed following the battery of physical health-related tests in young people, ALPHA-Fitness (Assessing Levels of Physical Activity) [1]. The muscular strength was measured with the long jump test. Cardiovascular Endurance was measured with the 20-meter shuttle-run test (Course Navette). The number of completed periods was transformed into maximal oxygen uptake (VO $2 \mathrm{max}, \mathrm{ml} / \mathrm{kg} / \mathrm{min}$ ) through the Lèger equation [13]. In addition, weight $(\mathrm{kg})$ and height $(\mathrm{cm})$ were measured according to the protocols established in Ruíz et al. [1]. Both measures were carried out barefoot and in light clothing. As a derived variable, the BMI was calculated using the traditional Quetelet formula [weight $(\mathrm{kg}) /$ height2 (m)].

\subsection{Static analysis}

Anthropometric and fitness characteristics are presented in mean and standard deviation (SD) values unless otherwise noted. Differences between age in physical fitness variables (test) were analyzed by analysis of variance. To analyze the differences between sexes, by age group and body type in each of the physical fitness tests, the Student's T test was used. The degree of influence of body typology (overweight + obesity) on strength and cardiovascular endurance was calculated by the effect size analysis, which was quantified using the Hedges g statistic. The accepted level of significance was $p<0.05$. The data were analyzed with the SPSS program, version 22.0. 


\section{Results}

Anthropometric characteristics and fitness parameters are presented in Table 1. Descriptive analysis showed that boys had significantly more weight, height and BMI than girls ( $p$ $<0.05)$. Physical fitness is better in boys and these variables tend to increase with increasing age.

The results obtained in the standing long jump test showed significant differences between normalweight and overweight adolescents (all $\mathrm{p}<0.05$ ). In boys with overweight $(\mathrm{p}<0.001)$, only between $18 \%(\mathrm{~g}=0.927 ; 0.803)$ and $25 \%(\mathrm{~g}=0.677 ; 0.748)$ jumped a distance equal to or greater than normalweight students. However, in girls $(\mathrm{p}<0.01)$ the differences were more heterogeneous, accentuating during the 17 years, where only $17 \%$ (g $=0.95 ; 0.819)$ of them obtained a score equal to or lower than the normalweight students.

The results obtained in the 20-meter shuttle-run test showed that there are significant differences between normalweight and overweight adolescents $(\mathrm{p}<0.02)$, in all ages and both sexes. Only between $9 \%(\mathrm{~g}=1,21,0.91)$ and $19 \%(\mathrm{~g}=0.913 ; 0.82)$ of overweight boys obtained a VO2 max. equal or higher than normalweight students. However, in overweight women, only between the $23 \%(\mathrm{~g}=0.75 ; 0.78)$ and $35 \%(\mathrm{~g}=0.41 ; 0.66)$ obtained a VO2 max. equal to or higher than normalweight students.

\section{Discussion}

This study aimed to quantify the influence of body typology on the results of strength tests and cardiovascular endurance in adolescents within each age range. The results of the present study have shown that the level of fitness is greater in boys than girls. It has also been shown that there are significant differences between adolescents of both sexes with normalweight and with excess of weight in the results of strength and cardiovascular endurance. In standing long jump test, only between $18 \%-25 \%$ of overweight boys get a distance equal to or greater than normalweight students, while in girls it range was from $17 \%$ to $36 \%$. In the 20 -meter shuttle-run test, only $9-19 \%$ of overweight boys had a VO2 max. equal to or higher than normalweight peers, while in girls this range from $23 \%$ to $35 \%$. Therefore, the results suggest that it would be necessary to include the body type variable within the scales of assessment of strength and cardiovascular endurance in adolescents.

Our findings are similar to those obtained by previous studies that show that the body typology is determinant for the results of physical fitness. For example, Fogelholm et al., [10], indicated that overweight adolescents from Finland showed worse results of muscle strength and cardiovascular endurance than normalweight. However, excess of weight was associated to a lesser extent with motor skills. Similarly, Hsieh et al. [14], and Hanifah et al. [15], showed a high negative correlation between BMI and cardiovascular endurance in young men from Taiwan, Iran and Malaysia, respectively. In Spain, both muscle strength and cardiovascular endurance are negatively associated with total body fat and central body fat. However, strength was greater in overweight adolescents [16]. For some authors, overweight and obesity significantly affect the physical fitness level in adolescents [11]. Thus, it is especially important to establish adjustment measures in fitness batteries. So far, there are physical fitness scales based on sex and age in US youth [17], Australia [18], in some Asian countries [5, 14] and in Spain [6]. However, we have not found scales that include the body typology, therefore we cannot compare our findings with previous studies. Thus, the present study would be presented as an effective tool to improve the quality of the scales for Physical Education classes and thus, to improve the quality of teaching. 


\section{Conclusion}

It is concluded that only a low percentage of adolescents between 13-17 years, with overweight and obesity, obtain a result of strength and cardiovascular endurance equal to or higher than the normalweight students. Thus, these results suggest that it would be necessary to include the body type variable within the physical fitness scales in adolescents.

\section{References}

1. J.R. Ruiz, V. España Romero, J. Castro Piñero, E.G. Artero, F.B. Ortega, M. Cuenca García,..., M.J. Castillo, Nutrición Hospitalaria, 26, 6 (2011)

2. J.D. Secchi, G.C. García, V. España-Romero, J. Castro-Piñero, Archivos argentinos de pediatría, 2, 132 (2014)

3. J. Castro-Piñero, E.G. Artero, V. España-Romero, F.B. Ortega, M. Sjöström, J. Suni, J. R. Ruiz, British journal of sports medicine, 13, 934 (2010)

4. J.R. Gómez-Puerto, C.J. Berral de la Rosa, B.H. Viana Montaner, F.J. Berral de la Rosa, Archivos de medicina del deporte, 90, 273 (2002)

5. F.B. Ortega, E.G. Artero, J.R. Ruiz, V. España-Romero, D. Jiménez-Pavón, G. Vicente-Rodríguez,..., M.J. Castillo, British journal of sports medicine, 1, 20 (2011)

6. F.B. Ortega, J.R. Ruiz, M.J. Castillo, L.A. Moreno, M. González-Gross, J. Wärnberg, Á. Gutiérrez, Revista española de cardiología, 8, 898 (2005)

7. L.A. Moreno, M.I. Mesana, M. González-Gross, C.M. Gil, F.B. Ortega, J. Fleta, ..., M. Bueno, International Journal of Obesity, 12, 1798 (2007)

8. L. Serra-Majem, L. Ribas Barba, J. Aranceta Bartrina, C. Pérez Rodrigo, P. Saavedra Santana, L. Peña Quintana, Medicina clínica, 19, 725 (2003)

9. S. Plachta-Danielzik, B. Landsberg, M. Johannsen, D. Lange, M.J. Müller, Public health nutrition, 11, $1870(2010)$

10. M. Fogelholm, S. Stigman1, T. Huisman, J. Metsamuuronen, Scand J Med Sci Sports, 18, $162(2008)$

11. G. Botelho, M. Aguiar, C. Abrantes, Journal of Physical Education and Sport, 1, 19 (2013)

12. C. Fernández, H. Lorenzo, K. Vrotsou, Curvas y tablas de crecimiento (estudio transversal) (Bilbao: Fundación Faustino Orbegozo Eizaguirre (2011)

13. L.A. Leger, D. Mercier, C. Gadoury, J. Lambert, Journal of sports sciences, 2, 93 (1988)

14. P.L. Hsieh, M.L. Chen, C.M. Huang, W.C. Chen, C.H. Li, L.C. Chang, International Journal of Environmental Research and Public Health, 7, 7275 (2014)

15. R.A. Hanifah, H.A. Majid, M.Y. Jalaludin, N. Al-Sadat, L.J. Murray, M. Cantwell, ... A.M. Nahar, BMC Public Health, 14, S5 (2014)

16. D. Moliner-Urdiales, J.R. Ruiz, G. Vicente-Rodriguez, F.B. Ortega, J.P. Rey-Lopez, V. España-Romero, L.A. Moreno, British Journal of Sports Medicine, 2, 101 (2011)

17. J.C. Eisenmann, K.R. Laurson, G.J. Welk, American Journal of Preventive Medicine, 4, S106 (2011)

18. M. Catley, G.R. Tomkinson, British Journal of Sports Medicine, 2, 98 (2013) 